DOI: https://doi.org/10.36910/6775-2524-0560-2021-45-08

УДК 620.3

Харченко Наталя Сергіївна, студентка

https://orcid.org/0000-0002-8633-505X

Сердаковський Віталій Сергійович, старший викладач

Національний технічний університет України "Київський політехнічний інститут імені Ігоря Сікорського"

\title{
НЕЙРОННА МЕРЕЖА ДЛЯ ДІАГНОСТИКИ ХВОРОБИ ПАРКІНСОНА ЗА ЗОБРАЖЕННЯМ СПІРАЛІ АРХІМЕДА
}

\begin{abstract}
Харченко Н.С., Сердаковський В.С. Нейронна мережа для діагностики хвороби Паркінсона за зображенням спіралі Архімеда. У статті розглянуто актуальну проблему встановлення діагнозу Паркінсона на ранніх стадіях захворювання. Вибір теми дослідження обумовлено невиліковністю хвороби Паркінсона, отже вкрай гостро, на думку авторів є нагальне виявлення захворювання на ранніх стадіях. Констатовано, щуо діагностики, для точного встановлення діагнозу нині не існує, тому залишається проведення тестів для виявлення симптомів. Одним з таких, як слушно зауважують автори є малювання спіралі Архімеда, яке має доволі високу точність під час виявлення тремору спокою. Створення алгоритму для автоматичної обробки таких зображень може допомогти у проведені діагностики, а також моніторингу розвитку хвороби. Поєднання штучного інтелекту та інтернет медичних речей з часом зробить підключені пристрої для моніторингу стану здоров'я більш інтелектуальними. Нейронні мережі та величезні обсяги даних, що генеруються інтернет медичних речей, також можуть використовуватися для встановлення діагнозу. Авторами статті наголошено на фундаментальних можливостях нейронних мереж, їх сприятливій ролі у трансформачї̈ сфери радіології, иляхом заощадження часу та грошей медичних організацій. Розроблено нейронну мережу, яка зможе за зображенням намальованої спіралі Архімеда встановити діагноз. Дану мережу можна використовувати для проведення ранньої діагностики, а також подальшого моніторингу стану хвороби. Зважаючи на невелику вибірку зображень для навчання та тренування моделі авторами статті було прийняте рішення про збільшення вибірки шляхом перетворення зображень, а також використання згорткової нейронної мережі з попереднім навчанням. У результаті проведеної роботи було створено модель, яка має точність 93.7 відсотків яка дозволить автоматизувати процес діагностики хвороби на ранніх стадіях.
\end{abstract}

Ключові слова: хвороба Паркінсона, спіраль Архімеда, сегментачія зображення, нейронна мережа.

Харченко Н.С., Сердаковський В.С. Нейронная сеть для диагностики болезни Паркинсона за изображением спирали Архимеда. В статье рассмотрена актуальная проблема установления диагноза Паркинсона на ранних стадиях заболевания. Выбор темы исследования обусловлен неизлечимостью болезни Паркинсона, так что крайне остро, по мнению авторов, является неотложное выявление заболевания на ранних стадиях. Констатировано, что диагностики для точного установления диагноза сейчас не существует, поэтому остается проведение тестов для выявления симптомов. Одним из таких, как справедливо замечают авторы, является рисование спирали Архимеда, которое имеет достаточно высокую точность при обнаружении тремора покоя. Создание алгоритма для автоматической обработки таких изображений может помочь в проведении диагностики и мониторинга развития болезни. Сочетание искусственного интеллекта и интернет-медицинских вещей со временем сделает подключенные устройства для мониторинга состояния здоровья более интеллектуальными. Нейронные сети и огромные объемы данных, генерируемые интернет-медицинскими вещами, такюе могут использоваться для установления диагноза. Авторами статьи наложены на фундаментальные возможности нейронных сетей, их благоприятную роль в трансформации сферы радиологии, путем сбережения времени и денег медииинских организаций. Разработана нейронная сеть, которая сможет по изображению нарисованной спирали Архимеда установить диагноз. Данную сеть можно использовать для проведения ранней диагностики, а также для дальнейшего мониторинга состояния болезни. Ввиду небольшой выборки изображений для обучения и тренировки модели авторами статьи было принято решение об увеличении выборки путем преобразования изображений, а также использования сверточной нейронной сети с предварительным обучением. В результате проведенной работы была создана модель, имеющая точность 93.7 процентов, которая позволит автоматизировать процесс диагностики болезни на ранних стадиях.

Ключевые слова: болезнь Паркинсона, спираль Архимеда сегментация изображения, нейронная сеть.

Kharchenko N. S., Serdakovsky V. S. A neural network for diagnosis of Parkinson's disease according to the Archimedes spiral. The article considers the topical problem of diagnosing Parkinson's disease in the early stages of the disease. It is stated that there is no diagnosis for exact determination of the diagnosis now, so it remains to carry out tests to detect symptoms. The choice of the study topic is due to the incurability of Parkinson's disease, therefore, detection of the disease in its early stages, according to the authors, is extremely urgent. One of them, as the authors rightly note, is Archimedes spiral drawing, which has a rather high accuracy in detecting resting tremor. Creating an algorithm for automatic processing of such images can help in the diagnosis and monitoring of disease progression. The combination of artificial intelligence and Internet medical things will eventually make connected health monitoring devices more intelligent. Neural networks and the vast amounts of data generated by Internet medical things could also be used to make diagnoses. The authors of the article overlay the fundamental capabilities of neural networks and their favorable role in transforming the field of radiology, by saving time and money for medical organizations. A neural network has been developed that will be able to make a diagnosis based on the image of the drawn Archimedes spiral. This network can be used for early diagnosis and further monitoring of the disease. Due to a small sample of images for training and training of the model, the authors of the article decided to increase the sample by image transformation, as well as the use of

(C) Харченко Н.С., Сердаковський В.С. 
convolutional neural network with pre-training. As a result of this work, a model with 93.7 percent accuracy was created, which will allow to automate the process of diagnosing the disease in its early stages.

Key words: Parkinson's disease, Archimedes spiral image segmentation, neural network.

Вступ. Сучасна медицина зробила великий крок у діагностиці та лікуванню такого захворювання як Паркінсона. Хоча захворювання нині $\epsilon$ не виліковним, існують методи, які дозволяють призупинити іï розвиток та покращити життя хворих. Таке лікування дозволяє лише відтермінувати момент, коли хвороба повністю «заволодіє» нервовою системою людини. Тому процес лікування необхідно розпочинати якомога раніше, аби препарати призупиняли ії розвиток на ранніх стадіях. Найпершим симптомом хвороби являється тремор спокою. Він може проявлятися непомітно для самого хворого, що ускладнює діагностику. Помітний тремор вказує на те, що хвороба Паркінсона прогресує і лікування буде менш ефективним. Тому сучасна медицина головним чином працює над розробкою методів для діагностики хвороби на ранніх стадіях.

Діагностики, для точного встановлення діагнозу досі не існує, тому залишається проведення тестів для виявлення симптомів. Одним з таких них є малювання спіралі Архімеда, яке має доволі високу точність під час виявлення тремору спокою. Створення алгоритму для автоматичної обробки таких зображень може допомогти у проведені діагностики, а також моніторингу розвитку хвороби.

Аналіз досліджень. «Хвороба Паркінсона $\epsilon$ другим за частотою нейродегенеративним захворюванням людини (після хвороби Альцгеймера), загальна поширеність хвороби Паркінсона становить приблизно 200 випадків на 100000 населення. Зазвичай захворювання розвивається у похилому віці - після 60 років, у той же час приблизно у кожного десятого пацієнта БП маніфестує до 50 років, а у кожного двадцятого - до 40 років» [1].

У 5-10\% випадків причиною захворювання є мутації певних генів. Кожна генетична форма захворювання має особливості залежно від ураженого гена. Тип успадкування може бути як аутосомно-домінантним (і тоді захворювання, як правило, простежується в сім'ї), так і аутосомнорецесивним (у цьому випадку захворювання може виявитися в сім'ї вперше). Однак у переважній більшості випадків захворювання є спорадичним, і точна причина його розвитку на сьогоднішній день не відома.

Як при генетичній, так і при спорадичній формах хвороби Паркінсона в основі лежить накопичення патологічних форм особливого білка - альфа-синуклеїну, скупчення якого знаходять в уражених нервових клітинах [2]. Вони викликають порушення правильного функціонування нейронів і передаються від однієї області головного мозку до іншої, викликаючи прогрес захворювання та поширення симптомів. Одним із основних регіонів головного мозку, який уражається при хворобі Паркінсона, є чорна субстанція, загибель iï клітин призводить до основних рухових проявів захворювання. При цьому на сьогоднішній день показано, що захворювання не обмежується тільки цією областю і торкається багатьох інших регіонів головного мозку. Головною причиною інтересу до хвороби Паркінсона $є$ її невиліковність, отже необхідно виявлення захворювання на ранніх стадіях. Зважаючи на те що, за допомогою спіралі Архімеда можливо доволі точно встановити діагноз на ранніх стадіях, то можливість проведення такої діагностики за допомогою нейронної мережі допоможе у боротьбі з хворобою[3].

Мета статті. У даній роботі автори мають намір розробити та навчити нейронну мережі для встановлення діагнозу хвороби Паркінсона на ранніх стадіях за спіраллю Архімеда. Для досягення вище поставленої мети доцільно вирішити наступні завдання:

1. здійснити аналіз сучасних наукових праць стосовно проведення діагностики хвороби Паркінсона.

2.розробити нейронної мережі для обробки зображень намальованих спіралей та оцінити точності нейронної мережі.

Виклад основного матеріалу. Можливості нейронних мереж допомагають трансформувати сферу радіології, заощаджуючи час та гроші медичних організацій. Після того, як медичне зображення отримано за допомогою МРТ, комп'ютерної томографії, ультразвукового або рентгенологічного дослідження, лікар повинен проаналізувати його на наявність відхилень або ознак захворювань. Для виявлення скільки-небудь серйозного стану потрібна інтерпретація кількох візуалізаційних досліджень.

Після навчання 3 використанням великих наборів даних досліджень системи на основі штучного інтелекту здатні аналізувати медичні зображення та повідомляти про виявлені особливості, наприклад, невеликі пухлини, які людське око може втратити. Такі системи виявляють закономірності та надають інформацію про характеристики будь-яких відхилень від норми, заощаджуючи час лікаря.

(c) Харченко Н.С., Сердаковський В.С. 
У тих випадках, коли пацієнт має кілька знімків, зроблених протягом деякого часу, штучний інтелект також може аналізувати динаміку захворювання. Так, для перевірки роботи своєї системи на основі штучного інтелекту в корпорації Google провели експеримент: знімки запропонували вивчити шістьох сертифікованих радіологів. У тих випадках, коли діагноз ставився за єдиним знімком, штучний інтелект впорався так само або навіть краще за людей. Системі вдалося діагностувати на 5\% більше випадків раку та скоротити хибнопозитивні вердикти на 11\% [4].

Найбільша потенційна перевага штучного інтелекту - можливість допомогти людям залишатися бадьорими, щоб їм не доводилося відвідувати лікаря чи принаймні робити це не надто часто. Штучний інтелект та інтернет медичних речей вже поступово змінюють парадигму 3 «реактивної» охорони здоров'я на «проактивну».

Поєднання штучного інтелекту та інтернет медичних речей з часом зробить підключені пристрої для моніторингу стану здоров'я більш інтелектуальними. Нейронні мережі та величезні обсяги даних, що генеруються інтернет медичних речей, також можуть використовуватися для встановлення діагнозу.

Правильним інструментом для завдання класифікації зображень $є$ згорткова нейронна мережа [5], тож давайте спробуємо навчити його на наших даних як початковий базовий рівень. Оскільки ми маємо лише кілька прикладів, нашою проблемою номер один має бути переобладнання. Переобладнання відбувається, коли модель, на яку наведено занадто мало прикладів, вивчає закономірності, які не узагальнюються на нові дані, тобто коли модель починає використовувати нерелевантні функції для прогнозування. Наприклад, якщо ви, як людина, бачите лише три зображення людей, які є лісорубами, і три зображення людей, які є моряками, і серед них лише один лісоруб носить кашкет, ви можете подумати, що носити кепку - це ознака того, що ви лісоруб, а не моряк. Тоді ви зробили б досить паскудний класифікатор лісоруба/матроса [6, 10].

Збільшення даних є одним із способів боротьби з переобладнанням, але цього недостатньо, оскільки наші доповнені вибірки все ще дуже корелюють. Основна увага в боротьбі 3 переобладнанням має бути на ентропійній ємності моделі - скільки інформації дозволено зберігати вашій моделі. Модель, яка може зберігати багато інформації, може бути більш точною, використовуючи більше функцій, але вона також ризикує почати зберігати невідповідні функції. Між тим, модель, яка може зберігати лише кілька функцій, повинна буде зосередитися на найбільш значущих ознаках, знайдених у даних, і вони, швидше за все, будуть справді релевантними та краще узагальнювати [9].

Існують різні способи модуляції ентропійної ємності. Основним з них є вибір кількості параметрів у вашій моделі, тобто кількості шарів і розміру кожного шару. Іншим способом $\epsilon$ використання регуляризації ваг, наприклад L1 або L2, яка полягає в примусовому примусовому примушуванні ваг моделі приймати менші значення [8].

У нашому випадку ми будемо використовувати дуже невелику мережу з кількома шарами i кількома фільтрами на шар, поряд із збільшенням даних і випаданням. Відмова також допомагає зменшити переобладнання, не даючи шару бачити двічі однаковий шаблон, таким чином діючи аналогічно доповненню даних (ви можете сказати, що як відсівання, так і збільшення даних, як правило, порушують випадкові кореляції, що виникають у ваших даних).

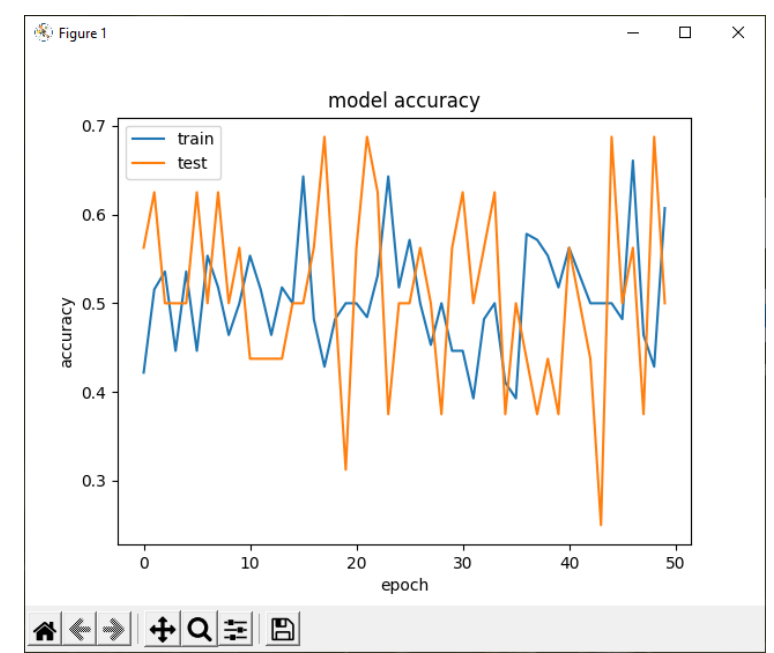

Рис. 1. Результат навчання невеликої нейронної мережі

(C) Харченко Н.С., Сердаковський В.С. 
Наступним кроком буде використання функцій вузького місця попередньо навченої мережі. Більш досконалим підходом було б використовувати мережу, попередньо навчену на великому наборі даних. Така мережа вже засвоїла б функції, корисні для більшості проблем комп’ютерного зору, і використання таких функцій дозволило б нам досягти кращої точності, ніж будь-який метод, який покладався б лише на доступні дані.

Стратегія буде наступною: створимо лише згорткову частину моделі, все до повністю пов'язаних шарів. Потім запустимо цю модель на даних навчання та перевірки один раз, записавши вихід (“характеристики вузького місця" з моделі VGG: останні карти активації перед повністю підключеними шарами) у двох масивах чисел. Потім навчимо невелику повністю підключену модель поверх збережених функцій.

У якості згорткової мережі було вирішено обрати саме VGG, адже вона може досягати точності до 92.7\% під час тестування на задачах розпізнавання об'єктів на зображенні [6, 7].

Причина, чому ми зберігаємо функції в автономному режимі, а не додаємо нашу повністю підключену модель безпосередньо на заморожену згорткову базу і запускаємо все, полягає в ефективності обчислень. Запуск VGG дорогий, особливо якщо ви працюєте на ЦП, і ми хочемо зробити це лише один раз. Зауважте, що це не дозволяє нам використовувати розширення даних.

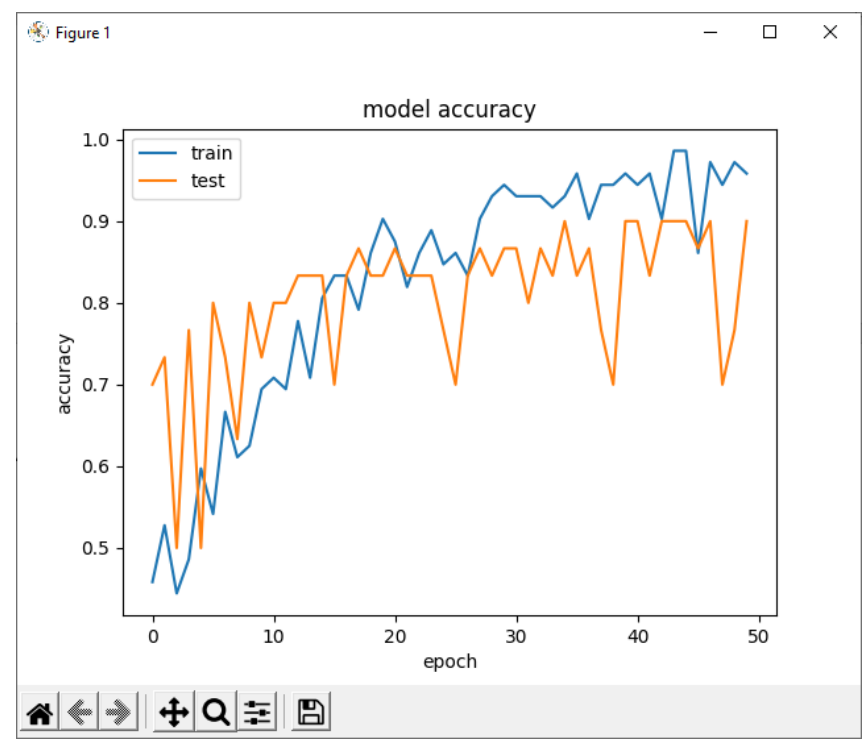

Рис. 2. Навчання за допомогою згорткової нейронної мережі

На малюнку 2 видно, що результати навчання мають більш точні показники, и на епоха 50 нам вдалося отримати точність 90\%. Отже, мі зберігаємо ваги цієї мережі та будемо використовувати їх для подальшого навчання нейромережі.

Виконуємо останній крок, який представляє 3 себе тонке налаштування верхніх шарів попередньо навченої мережі. Щоб ще більше покращити наш попередній результат, ми можемо спробувати «точно налаштувати» останній згортковий блок моделі VGG19 поряд з класифікатором верхнього рівня. Таке налаштування полягає в тому, щоб почати 3 навченої мережі, а потім перенавчати ії на новому наборі даних з використанням дуже малих оновлень. У нашому випадку це можна зробити в 3 кроки:

- $\quad$ с створити екземпляр згорткової бази VGG19 і завантажити іiї ваги;

- д додайте нашу попередньо визначену повністю підключену модель зверху та завантажте її ваги;

- заморозити шари моделі VGG19 до останнього згорткового блоку. 


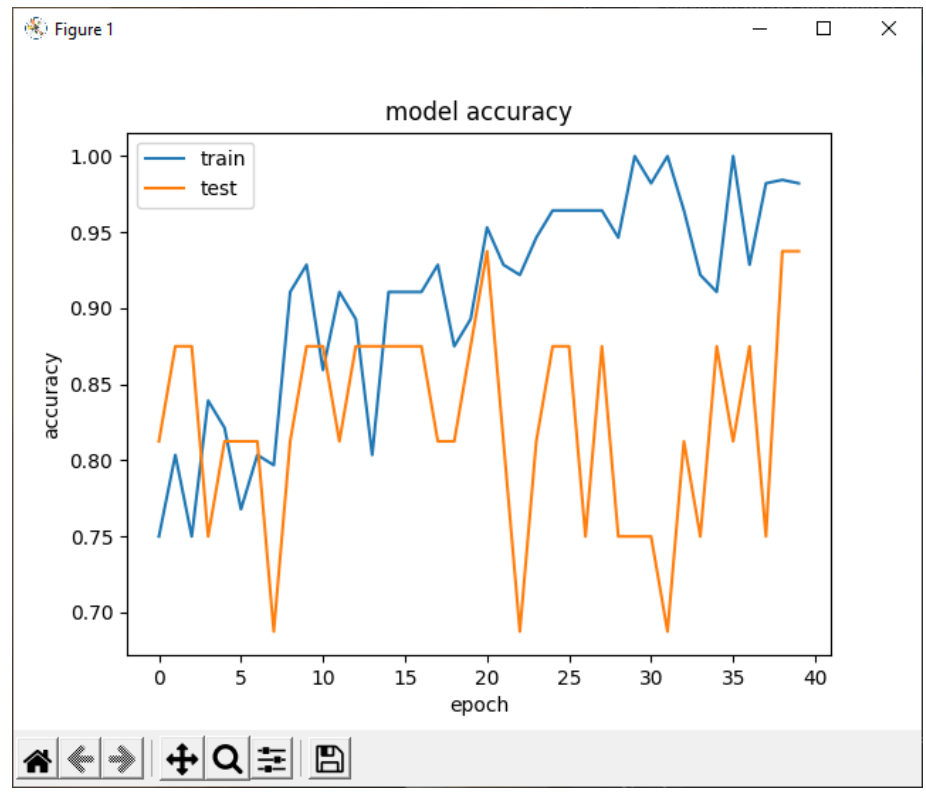

Рис. 3. Результат навчання нейронної мережі після налаштування верхніх шарів

На малюнку видно, що цього разу було проведено лише 40 епох, щоб запобігти перенавчанню нейронної мережі. В результаті, цього було отримано точність у 93.7\%.

Висновки. Отже, в вищенаведеній роботі було створено нейронну мережу для діагностики хвороби Паркінсона. Зважаючи на невелику вибірку зображень для навчання та тренування моделі було прийняте рішення про збільшення вибірки шляхом перетворення зображень, а також використання згорткової нейронної мережі з попереднім навчанням. У результаті проведеної роботи було створено модель, яка має точність 93.7 відсотків. Така модель дозволить автоматизувати процес діагностики хвороби на ранніх стадіях.

Список бібліографічного опису.

1. Болезнь Паркинсона. Научный центр неврологии. URL: https://www.neurology.ru/simptomy-i-zabolevaniya/boleznparkinsona (дата обращения: 30.11.2021)

2. Пчелина С. Н. Альфа-синуклеин как биомаркер болезни Паркинсона. Аннальь клинической и экспериментальной неврологии. 2011. №4. URL: https://cyberleninka.ru/article/n/alfa-sinuklein-kak-biomarker-bolezni-parkinsona (дата обращения: 30.11.2021).

3. Левин О.С., Артемьев Д.В., Бриль Е.В., Кулуа Т.К. Болезнь Паркинсона: современные подходы к диагностике и лечению. Практическая медицина. 2017. №1 (102). URL: https://cyberleninka.ru/article/n/bolezn-parkinsona-sovremennyepodhody-k-diagnostike-i-lecheniyu (дата обращения: 30.11.2021).

4. Харченко Н. С., Сердаковський В. С. Ознайомчий аналіз методів діагностики хвороби Паркінсона та покращення алгоритму для обробки оцифрованого зображення спіралі Архімеда. Міжнародний науковий журнал "Інтернаука». 2021. №8. URL: https://www.inter-nauka.com/uploads/public/16245399295923.pdf (дата звернення: 30.11.2021).

5. Землевский А. Д. Исследование архитектуры сверточных нейронных сетей для задачи распознавания образов. Вестник науки и образования. 2017. №6 (30). URL: https://cyberleninka.ru/article/n/issledovanie-arhitektury-svertochnyhneyronnyh-setey-dlya-zadachi-raspoznavaniya-obrazov (дата обращения: 30.11.2021).

6. Сравнение фреймворков для глубокого обучения: TensorFlow, PyTorch, Keras, MXNet, Microsoft Cognitive Toolkit, Caffe, etc. URL: https://habr.com/ru/company/otus/blog/443874/ (дата обращения: 30.11.2021).

\section{References.}

1. Pahwa R., Lyons K. E. Early diagnosis of Parkinson's disease: recommendations from diagnostic clinic guidelines $A m J$ Manag Care. 2010. Vol. 16 (4). P. 94-99.

2. Hughes R. C. Parkinson's Disease and its Management. BMJ: British Medical Journal. 1994. Vol. 308(6923). P. 281.

3. Rizek P., Kumar N., Jog M. S. An update on the diagnosis and treatment of Parkinson disease. Cmaj. 2016. Vol. 188(16). P. 1157-1165.

4. An early diagnosis is not the same as a timely diagnosis of Parkinson's disease / R. N. Rees et al. F1000Research. 2018. Vol. 7. P. 1106. URL: https://doi.org/10.12688/f1000research.14528.1 (date of access: 29.11.2021). 